Article

\title{
Salmonella spp. in Pigs Slaughtered in Small and Medium-Sized Abattoirs in Central Italy: Preliminary Results on Occurrence and Control Strategies
}

\author{
Sara Primavilla ${ }^{1,+} \mathbb{D}^{\mathbb{D}}$, Rossana Roila $^{2, *,+}{ }^{\mathbb{D}}$, Alessia Zicavo ${ }^{1}$, Roberta Ortenzi ${ }^{1}$, Raffaella Branciari ${ }^{2, *} \mathbb{0}$, \\ Tana Shtylla Kika ${ }^{3}$, Andrea Valiani ${ }^{1}$ and David Ranucci ${ }^{2}$ \\ 1 Istituto Zooprofilattico Sperimentale Togo Rosati, via Salvemini 1, 06121 Perugia, Italy; \\ s.primavilla@izsum.it (S.P.); a.zicavo@izsum.it (A.Z.); r.ortenzi@izsum.it (R.O.); a.valiani@izsum.it (A.V.) \\ 2 Department of Veterinary Medicine, University of Perugia, via San Costanzo 4, 06121 Perugia, Italy; \\ david.ranucci@unipg.it \\ 3 Department of Veterinary Publich Health, Faculty of Veterinary Medicine, Agricultural University of Tirana, \\ Kodër Kamëz, SH1, 1000 Tiranë, Albania; tana.shtylla@ubt.edu.al \\ * Correspondence: rossana.roila@unipg.it (R.R.); raffaella.branciari@unipg.it (R.B.) \\ + Sara Primavilla and Rossana Roila equally contributed and both are first-author.
}

check for

updates

Citation: Primavilla, S.; Roila, R.; Zicavo, A.; Ortenzi, R.; Branciari, R.; Shtylla Kika, T.; Valiani, A.; Ranucci, D. Salmonella spp. in Pigs Slaughtered in Small and Medium-Sized Abattoirs in Central Italy: Preliminary Results on Occurrence and Control Strategies. Appl. Sci. 2021, 11, 7600. https:// doi.org/10.3390/app11167600

Academic Editor: Antonio Valero

Received: 26 July 2021

Accepted: 17 August 2021

Published: 19 August 2021

Publisher's Note: MDPI stays neutral with regard to jurisdictional claims in published maps and institutional affiliations.

Copyright: (c) 2021 by the authors. Licensee MDPI, Basel, Switzerland. This article is an open access article distributed under the terms and conditions of the Creative Commons Attribution (CC BY) license (https:// creativecommons.org/licenses/by/ $4.0 /)$.

\begin{abstract}
Salmonella in pork is still a relevant safety issue in the EU, and specific regulations are in force to control this hazard in the meat chain, in a from farm to fork perspective. In Italy, the control is mainly based on official sampling at the slaughterhouse level. The prevalence of Salmonella, and isolated serovars, was investigated during a three-year survey in small and medium slaughterhouses in central Italy. A total of 400 pig carcasses samples were collected by official authorities during the observation period. Data were also analyzed according to the year and season of sampling. The overall Salmonella prevalence in the five selected abattoirs was $13 \%$, with no differences due to the slaughterhouses size and seasons of sampling. An increasing trend in Salmonella prevalence was registered over the years. The main serovars detected were Salmonella enterica 4,[5],12:i:- and Derby. The data emphasized that the number of contaminated carcasses is relatively high with respect to the level set by EU legislation, and equally distributed in the area, and therefore, appropriate monitoring and control strategies also need to be developed at the farm level.
\end{abstract}

Keywords: food safety; Salmonella serovars; slaughterhouse; pig carcasses

\section{Introduction}

Among foodborne bacteria, Salmonella has in recent decades been globally considered a food safety issue. According to the 2021 European Center for Disease Control (ECDC)-European Food Safety Authority (EFSA) summary report on zoonoses, it represents the second most frequently reported zoonotic agent in the European Union (EU), with 87,923 confirmed cases in 2019 and a stable trend during 2015-2019 [1]. In the same year, Salmonella was identified in 926 food-borne outbreaks (17.9\% of the total number of outbreaks) that together affected 9169 people in the EU, with 1915 hospitalizations and seven deaths. Outside the EU, the safety issue related to salmonellosis is characterized by different impacts on public health [1]. In Brazil, this pathogen was found to be responsible for $11 \%$ of investigated foodborne diseases between 2009 and $2018 ; 2.1 \%$ of reported cases were attributable to pork meat and meat products [2]. The U.S. Centers for Disease Control and Prevention (CDC) estimates that Salmonella causes 1 million cases of foodborne illness every year in the United States, with 113 outbreaks in 2017 accounting for 29\% of confirmed single-pathogen outbreaks [3]. Data from Australia estimated more than 39,000 foodborne salmonellosis cases, of which $2.5 \%$ were attributable to a porcine source [4]; furthermore, the incidence of human salmonellosis continues to rise every year in Australia [5]. In China, 
it has been calculated that $22.16 \%$ of bacterial foodborne illnesses between 1994 and 2005 were caused by Salmonella [6].

Although the highest levels of Salmonella-positive food samples are attributable to poultry production (meat products and eggs) [1], pork is considered the major source of infection in humans in some EU countries, including Italy [7-10]. About this, among 265 strong-evidence foodborne salmonellosis outbreaks (FSO), pig meat and products thereof were responsible for $9.8 \%$, thus representing the type of meat most associated with salmonellosis in humans [1].

Salmonella can colonize pigs' gut, although most of them remain healthy carriers and the stress related to farm management, transportation, and early slaughtering stages (from unloading to stunning) may increase the prevalence of infected pigs entering the slaughtering process [11-13]. When animals are processed, contamination of pig carcasses can result from the skin, the intestinal contents, infected tissues, other carcasses, or slaughterhouse surfaces [14-16]. Consequently, the contamination/cross-contamination of carcasses, and therefore meat, represents a crucial way for the pathogen to enter the food chain and therefore a significant food-safety hazard [17].

The dynamic of the diffusion of Salmonella in the pork chain is often reported with an emphasis on the serotype most frequently involved, their origin, and correlation to animal source $[1,18]$. According to EFSA, the three most common serovars detected in pigs are S. enterica serovar 4,[5],12:i:- (the monophasic variant of Typhimurium) (28.8\%), S. enterica serovar Derby (24.1\%), and S. enterica serovar Typhimurium (12.7\%) [1]. As regards pig meat, the top three serovars detected are S. enterica serovar 4,[5],12:i:- (26.6\%), S. enterica serovar Derby (21,3\%), and S. enterica serovar Typhimurium (14\%) [1]. However, the majority (72.4\%) of the FSO are caused by S. enterica serovar Enteritidis [1].

Food hazards, including Salmonella, can occur at any point from farm to fork, so food safety standards are needed to ensure the safety of the global food supply chain. In the pork meat chain, the management and monitoring of the most probable critical point are important to design preventive and corrective measures to decrease the frequency of contaminated carcasses at the end of the slaughtering process [12].

The contribution of different factors to the presence and prevalence of Salmonella in pigs has been investigated in depth at the farm level, during transport, and at the abattoir [19], and key areas to be monitored have already been proposed [14,20,21], mostly relating to industrial production that involves high-capacity slaughterhouses. Moreover, the literature also takes into consideration small slaughterhouses serving local farms [22].

Therefore, a chain approach is considered crucial to controlling Salmonella in pork production, as already secured for poultry [1]. In this context, following a request from the European Commission, the EFSA Panel on Biological Hazards was asked to deliver a Scientific Opinion on the public health biological hazards to be covered by the inspection of swine meat [21]. It was concluded that preventive measures and controls, applied both on the farm and at the abattoir, are the only way to ensure effective control of the main hazards and comprehensive pork safety. The EFSA has also provided technical assistance on harmonized epidemiological criteria for specific public health hazards in food and animals to be used by risk managers, including Salmonella. The epidemiological indicators can be used by the European Commission and the Member States in the pork safety assurance framework [23]. As regards Salmonella in pigs, seven harmonized epidemiological indicators have been selected, considering different food chain stages: farm, transport, and slaughterhouse. Microbiological testing and typing of Salmonella spp. in carcass swabs will also provide data on specific new zoonotic serovars, such as $S$. enterica 4,[5],12:i:- and new emerging serovars of special public health significance [23].

The present study was conducted to investigate, based on official control data and during a three-year observation, the prevalence of pig carcasses' contamination with Salmonella in small and medium-sized slaughterhouses located in central Italy devoted to the slaughtering of animals mainly from local farms. Data were also analyzed by seasons of the year to define a possible relationship between prevalence and environmental conditions. 
Our hypothesis is that, in the lack of compulsory Salmonella monitoring and control plan at the preslaughter stage, the prevalence of Salmonella in the carcasses is unlikely to decrease. The diffusion of the Salmonella serovars was also investigated to define their evolution during the observed period.

\section{Materials and Methods}

\subsection{Sample Collection}

Pig carcass samples collected in Umbria (central Italy) between 2017 and 2019 were analyzed by the Istituto Zooprofilattico Sperimentale of Umbria and Marche "Togo Rosati". The samples came from the Competent Authority National Program for Salmonella undertaken in accordance with Regulation (EC) No. 2073/2005 and performed in three small-sized slaughterhouses (slaughtering fewer than 5000 animals per year from small, local farms) and two medium-sized slaughterhouses (slaughtering between 5000 and 50,000 animals per year, from both small and finishing farms) [24]. The sampling plan was defined according to Regulation (EC) No. 218/2014 with an average of 49 samples per year from the medium-sized slaughterhouse and 12 samples per year from the small ones [25]. A total of 400 carcass samples were collected during the observation period with sterile premoistened sponges rubbed over the half-carcass surface before chilling (EC regulation 2073/2005), and sponge samples were transported to the laboratory in thermal boxes, stored at $4^{\circ} \mathrm{C}$, and processed within $24 \mathrm{~h}$ [24].

\subsection{Isolation, Identification, and Serotyping}

Sponge samples were pre-enriched in $90 \mathrm{~mL}$ of buffered peptone water (Biolife Italiana s.r.l., Milan, Italy) and incubated for $16-22 \mathrm{~h}$ at $37 \pm 1{ }^{\circ} \mathrm{C}$. One hundred microliters of the pre-enrichment broth was transferred aseptically into $10 \mathrm{~mL}$ of SX2 broth (bioMérieux, Marcy-l'Etoile, France) and incubated for $22-26 \mathrm{~h}$ at $41.5 \pm 1{ }^{\circ} \mathrm{C}$. Salmonella detection was then performed through an alternative method validated by AFNOR (AFNOR BIO 12/10-09/02) based on enzyme-linked fluorescent immunoassay by means of VIDAS ${ }^{\circledR}$ SLM test (bioMérieux), following the instructions provided by the manufacturer [26]. According to UNI EN ISO 6579:2017, Salmonella was isolated from the positive broth cultures through selective and differential media (xylose lysine deoxycholate agar, Microbiol s.r.l., Cagliari, Italy; and Salmonella chromogenic medium, Biolife Italiana s.r.1.) [27]. After incubation at $37 \pm 1{ }^{\circ} \mathrm{C}$ for $24 \mathrm{~h}$, each medium was examined to identify the presence of typical Salmonella colonies: red colonies, with black center on xylose-lysine-deoxycholate agar and magenta colonies on Salmonella chromogenic medium. Biochemical tests (API 20E stripsbioMérieux) were used to confirm typical colonies. The Salmonella isolates, incubated at $37 \pm 1{ }^{\circ} \mathrm{C}$ for $24 \mathrm{~h}$ in trypticase soy agar (TSA) (Oxoid Ltd., Basingstoke, UK) were finally serotyped according to the White-Kauffmann-Le Minor scheme by performing a slide agglutination test with polyvalent and monovalent antisera against somatic $(\mathrm{O})$ and phase 1 and phase 2 flagellar (H) antigens (SSI diagnostics, Hillerød, Denmark) [28].

\subsection{Statistical Analysis}

Data were gathered on overall prevalence and analyzed by factors such as year (2017, 2018, and 2019), slaughterhouse capacity (small slaughterhouse ( $<5000$ animals per year) = SMS; medium-sized slaughterhouse (between 5000 and 50,000 animals per year) = MDS), and season (spring and summer $=$ SS; autumn and winter $=\mathrm{AW}$ ). All the statistical analyses were determined by EpiInfo 7.2 free software [29]. Calculation of 95\% confidence intervals (CIs) was performed by binomial distribution. The relation of the Salmonella prevalence and the different years, slaughterhouses, and seasons were calculated using Pearson Chi-square and Fisher's exact tests (significance set at $p<0.05$ ) [30,31]. Odd ratios were also calculated according to user's manual [29]. The same tests were adopted for the two major Salmonella serotype detected, as the number of samples for the minor serotypes was not sufficient for a proper statistical analysis. 


\section{Results}

A total of 400 carcasses were assessed over the three-year period considered; of these, 107 samples were referred to the SMS and 298 to the MDS. The distribution according to the season was 222 samples in SS and 178 in AW. The carcasses sampled in 2017, 2018, and 2019 numbered 133, 134, and 133, respectively.

The overall prevalence recorded in the carcasses was $13 \%(\mathrm{CI}=9.7-16.3 \%)$, with 52 samples positive for Salmonella spp. The results according to season and slaughterhouse capacity are reported in Figure 1. No difference was recorded in terms of the prevalence of Salmonella in relation to either the slaughtering capacity or season.

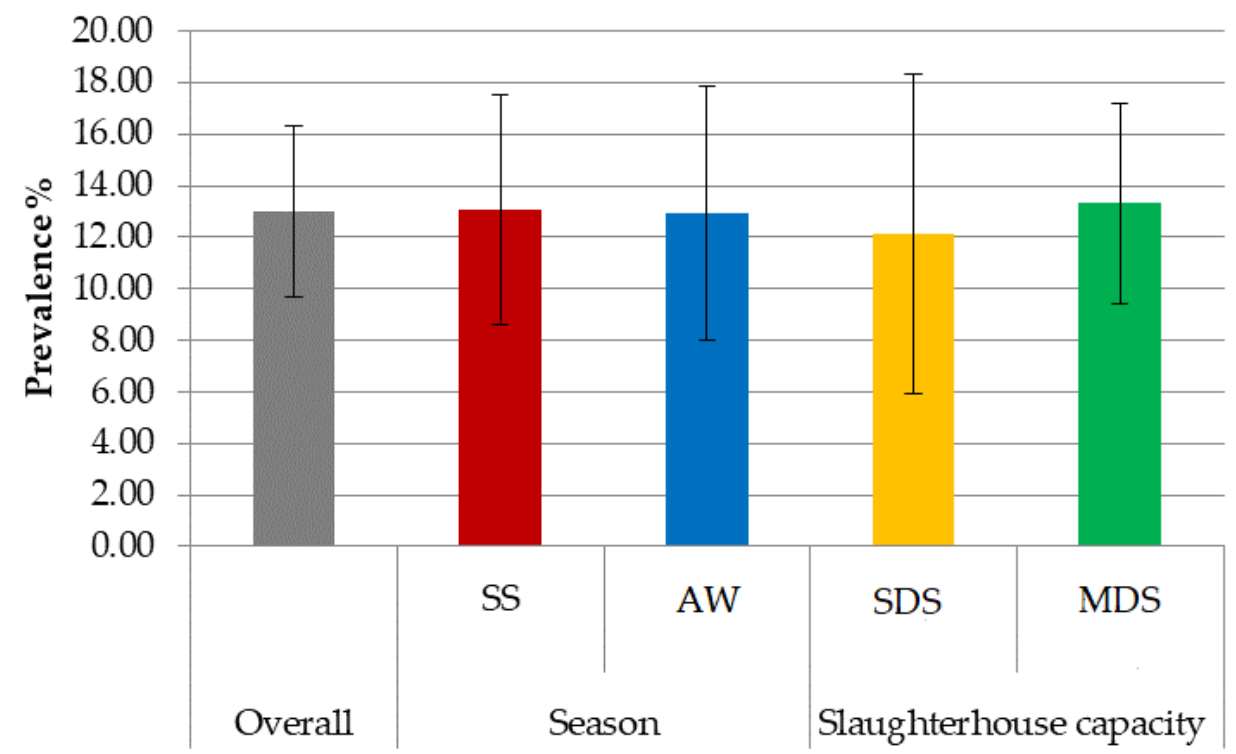

Figure 1. Overall prevalence (\%) and 95\% CI (bars) of pig carcasses positive for Salmonella according to season and slaughterhouse capacity. SS = Spring-Summer; AW = Autumn-Winter; SDS = small-sized slaughterhouse (<5000 pigs/year); MDS = medium-sized slaughterhouse (5000-50,000 pigs/year).

The prevalence results for each of the selected years are reported in Figure 2. A significant increase was recorded between 2017 and $2018(p<0.05)$ with an OR of 2.36, but not in 2019 .

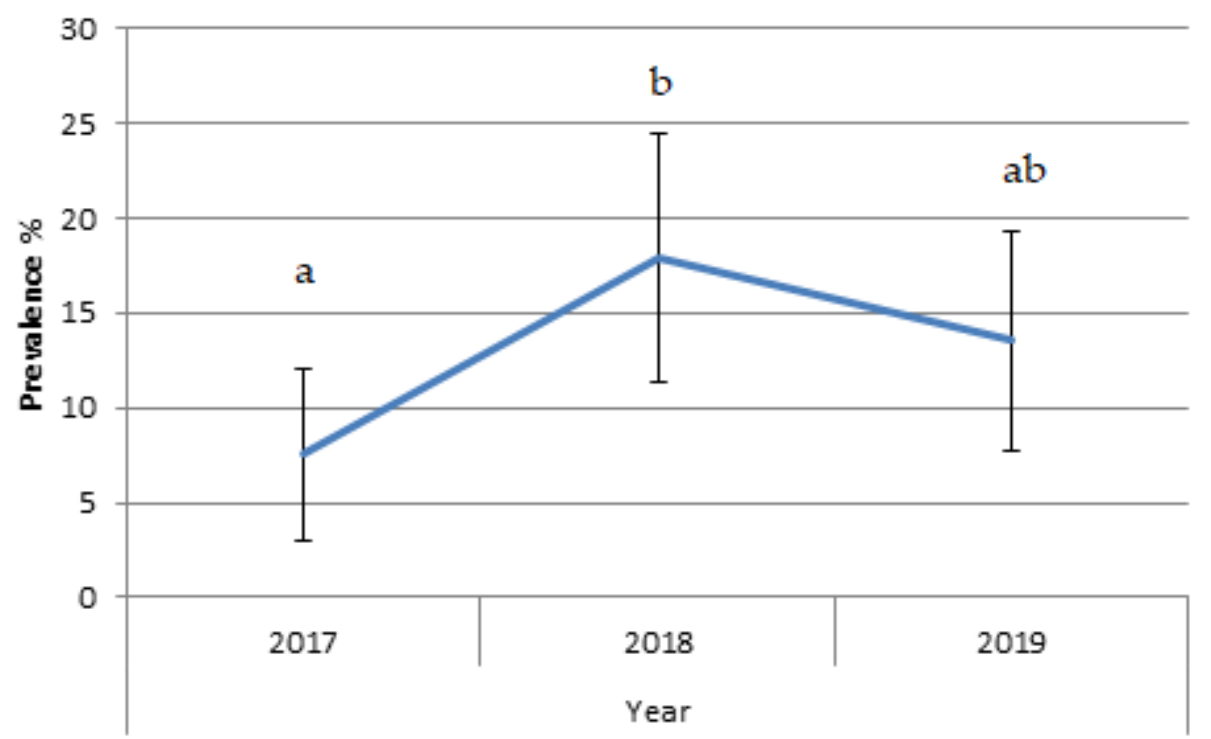

Figure 2. Prevalence (\%, CIs) of pig carcasses positive for Salmonella according to the year of sampling. $\mathrm{a}, \mathrm{b}=$ different letters indicate differences between years. 
The prevalence of the different Salmonella serovars even according to season and abattoir capacity is reported in Table 1.

Table 1. Percentage of Salmonella serotypes isolated from pig carcasses according to season and slaughterhouse capacity.

\begin{tabular}{|c|c|c|c|c|c|}
\hline \multirow[b]{2}{*}{$\begin{array}{c}\text { Salmonella } \\
\text { Serovars }\end{array}$} & \multirow{2}{*}{$\begin{array}{l}\text { Overall } \\
\begin{array}{l}(\%) \\
(n=45)\end{array}\end{array}$} & \multicolumn{2}{|c|}{ Season } & \multicolumn{2}{|c|}{ Slaughterhouse Capacity } \\
\hline & & $\begin{array}{c}\text { Spring/Summer } \\
(\%) \\
(n=25)\end{array}$ & $\begin{array}{l}\text { Autumn/Winter } \\
\begin{array}{c}(\%) \\
(n=20)\end{array}\end{array}$ & $\begin{array}{c}<5000 \\
\text { Animals/Year } \\
(\%) \\
(n=8)\end{array}$ & $\begin{array}{c}5000-50,000 \\
\text { Animals/Year } \\
(\%) \\
(n=37)\end{array}$ \\
\hline 4,[5],12:i:- & 33.33 & 36.00 & 30.00 & 50.00 & 29.73 \\
\hline Derby & 40.00 & 44.00 & 35.00 & 25.00 & 43.24 \\
\hline Infantis & 2.22 & 0.00 & 5.00 & 0.00 & 2.70 \\
\hline Bredeney & 4.44 & 4.00 & 5.00 & 0.00 & 5.41 \\
\hline Typhimurium & 2.22 & 4.00 & 0.00 & 12.50 & 0.00 \\
\hline Give & 2.22 & 0.00 & 5.00 & 12.50 & 0.00 \\
\hline London & 4.44 & 0.00 & 10.00 & 0.00 & 5.41 \\
\hline Rissen & 6.67 & 4.00 & 10.00 & 0.00 & 8.11 \\
\hline Brandeburg & 2.22 & 4.00 & 0.00 & 0.00 & 2.70 \\
\hline Goldcoast & 2.22 & 4.00 & 0.00 & 0.00 & 2.70 \\
\hline
\end{tabular}

Among the 52 positive samples, an identification was obtained for 45 isolates ( 7 remained unidentified). The most diffused serovars were $S$. enterica serovar Derby and S. enterica serovar 4,[5],12:i:-, together representing over $70 \%$ of the isolates. A similar prevalence was registered for these two serotypes according to abattoir capacity and sampling season. The prevalence of the two major Salmonella serovars was similar across the three years of observation.

The minor serovars detected were Infantis, Bredeney, Typhimurium, Give, London, Rissen, Brandeburg, and Goldcoast. Typhimurium and Give were detected only in small slaughterhouses and the other serovars were detected only in the medium-sized abattoirs. The distribution according to the seasons was Infantis, Give, and London only in AW and Typhimurium only in SS. Infantis was isolated only in 2017; Bredeney, Typhimurium, and Give only in 2018; and London, Rissen, Brandeburg, and Goldcoast in 2019.

The distribution of Salmonella serovar according to the year of sampling is reported in Table 2.

Table 2. Percentage of Salmonella serotypes isolated from pig carcasses according to the year of sampling.

\begin{tabular}{cccc}
\hline $\begin{array}{c}\text { Salmonella } \\
\text { Serovars }\end{array}$ & $\begin{array}{c}\mathbf{2 0 1 7} \\
\mathbf{( \% )} \\
(\boldsymbol{n}=\mathbf{8})\end{array}$ & $\begin{array}{c}\mathbf{2 0 1 8} \\
\mathbf{( \% )} \\
(\boldsymbol{n}=\mathbf{2 1 )}\end{array}$ & $\begin{array}{c}\mathbf{2 0 1 9} \\
\mathbf{( \% )} \\
(\boldsymbol{n}=\mathbf{1 6 )}\end{array}$ \\
\hline 4,[5],12:i:- & 50.00 & 23.80 & 37.50 \\
Derby & 37.50 & 57.10 & 18.80 \\
Infantis & 12.50 & 0.00 & 0.00 \\
Bredeney & 0.00 & 9.50 & 0.00 \\
Typhimurium & 0.00 & 4.80 & 0.00 \\
Give & 0.00 & 4.80 & 0.00 \\
London & 0.00 & 0.00 & 12.50 \\
Rissen & 0.00 & 0.00 & 18.80 \\
Brandeburg & 0.00 & 0.00 & 6.30 \\
Goldcoast & 0.00 & 0.00 & 6.30 \\
\hline
\end{tabular}

\section{Discussion}

The results denote a level of contamination of the carcasses higher than that set by EU legislation as process hygiene criteria for pig slaughtering [24]. The results are even higher than those reported from pig carcasses by the ECDC and EFSA (3.88\%) [1] but are in line 
with results obtained by other authors in extra-EU, EU, and Italian abattoirs [14,22,32-35]. Nonetheless, where specific national guarantee plans are in force, including monitoring at the farm level (e.g., in Finland, Denmark, and Sweden) [19], the Salmonella prevalence drops to near zero [1].

When a high prevalence is detected by CA at a slaughterhouse, some concerns have to be considered. Even if the literature reports that the chilling of the carcasses could decrease the level of Salmonella-positive samples [15], the higher the prevalence in the carcasses, the more likely the presence of Salmonella after chilling [36], with a possible safety impact on the subsequent steps of the meat chain. In this context, the absence of Salmonella in the final products at the market level, as set by the EU legislation [24], may not be achieved, and the risk to consumers increases.

Nonetheless, the results consequent to the official control were sent each year to the FBOs to implement corrective action at the abattoirs, even if self-monitoring analyses always reveal compliance with the process hygiene criteria $(<6 \%$ of positive carcass samples; data not shown). This discrepancy between the official results and FBOs' self-monitoring results is also stressed by ECDC EFSA reports and needs further investigation [1]. Despite the efforts and proper hygiene practices implemented at the selected abattoirs, inconclusive results were obtained in these three years. Moreover, the presence of a similar prevalence in small and medium-sized abattoirs, where a different approach to slaughtering procedures and HACCP implementation could affect the contamination level [22], brings the core of the problem back on the farm and the pre-slaughter level [13,22]. For this reason, a limited efficacy of preventive action (implementing good hygiene and manufacturing practices, and risk management procedures) could be obtained during slaughtering to control contamination, even though it is considered crucial to avoid carcass crosscontamination [36]. A combined farm-abattoir approach would likely have cumulative benefits $[13,37]$. Furthermore, the European approach to meat safety involves the prevention of carcass contamination through proper implementation of hygienic procedures as no pig carcass treatments are allowed [38]. Additionally, even if it is generally reported that large farms of finishing herds are more prone to high Salmonella prevalence than small farms (farrow to finish), other aspects, such as farm management and structures, and the implementation of biosafety measures, could have an impact on Salmonella prevalence and mitigate the differences, as reported in the present study [39]. Moreover, other important factors that have to be monitored, such as the transport and holding at the abattoir, could spread contamination among animals of the same batch before slaughtering [16].

The abovementioned hypotheses could be corroborated by the absence of seasonal differences, which could be due to the high presence of the hazard at the farm level [40]. These data are not in agreement with other authors who found a higher Salmonella prevalence in pig herds during the fall in the USA, compared to the spring and summer, but was due to seasonal contamination at a feed mill [41].

The results of the identification of the serovar confirm that the major ones are Derby and 4,[5],12:i:-, which are the two serovars typically isolated from pigs [1].

No difference was registered for the two main S. enterica serovars detected according to the considered factors; their presence was equally distributed between small and mediumsized abattoirs, and between the different seasons. Uneven distribution of minor strains, in terms of slaughterhouse size, season, and year, was observed. In particular, medium-sized abattoirs showed greater variability in the detected serovars than small ones. The larger number of animals slaughtered could be responsible for a greater probability of finding different serovars [42], but further investigation is needed.

Integrated surveillance based on the "One Health" approach, combined with effective containment measures along the entire food chain (based on the application of biosecurity measures, effective surveillance and vaccination at the farm level, good manufacturing, and hygienic practices during slaughtering and food processing, and in the retail and consumer phases) is crucial to controlling the spread of Salmonella, especially the current and emergent epidemic clones [10]. Prior to the implementation of such interventions to 
prevent and manage Salmonella in pigs, it would be advisable to define specific, suitable, and harmonized sampling and testing strategies aiming to determine, with the highest possible degree of certainty, the real prevalence of Salmonella in the slaughterhouse [19]. In light of the above, the results of self-monitoring plans should be integrated with thorough surveillance by CAs. In this regard, following the EFSA suggested approach [23], the EU has set community targets for the reduction of the prevalence of zoonoses and zoonotic agents through national control programs [43], including pig breeding herds and herds of slaughtering pigs. The aims are to ensure that effective measures are taken to detect and control Salmonella at all relevant stages of production, processing, and distribution, in order to reduce its prevalence and public health risks. These control programs in pig herds are not harmonized between the Member States [19], so in some EU countries, such as Italy, to date, they are limited to the minimum sampling requirements: sampling only at slaughterhouse level [43] with a low number of samples collected and analyzed [44]. At this level, EU food safety legislation provides Food Safety Criteria and Process Hygiene Criteria, including for Salmonella [24], under the Food business operator (FBO), which has the primary responsibility for ensuring food safety and ought to verify compliance with these criteria through self-monitoring [45]. The FBO, therefore, has to guarantee that no more than $6 \%$ of carcasses are noncompliant with the process hygiene criterion (three nonconformities out of 50 samples) [46]. If the results are not compliant, the FBO must adopt corrective action on the overall production hygiene at the slaughterhouse level. As regards pork carcasses, the Competent Authority (CA) verifies whether the FBO has correctly implemented the Process Hygiene Criteria described by the EU legislation (in Regulation (EC) No. 2073/2005 (revised by Regulation (EC) No 217/2014) [24,46]. The Competent Authority must therefore perform sampling and analysis to verify this compliance by an official sampling using the same method and sampling areas as FBOs and taking at least 49 random samples from each slaughterhouse each year. If all are negative, $95 \%$ statistical certainty is achieved provided that the prevalence is below $6 \%$. This number of samples may be reduced in small slaughterhouses ( $<300$ pigs a week) based on a risk evaluation (one sample each month) [25]. Therefore, official monitoring at the slaughterhouse level is the only stronghold for the definition of the real situation in terms of Salmonella presence up to this point of the chain [47]. Nonetheless, the number of samples required to CA could be not sufficient to act properly as variations in Salmonella prevalence should be constantly monitored in order to carry out suitable counteractions [47]. However, it is of the utmost importance to assess the costs of possible preharvest interventions to control and manage Salmonella in pigs at different levels (feed, farm, transport, and slaughterhouse) and the benefits in terms of reductions in human and animal health costs [48].

\section{Conclusions}

The Salmonella prevalence in the examined context of both types of slaughterhouses in the central Italy area was higher than that allowed by EC regulation independent of the sampling year and seasons. The high levels detected throughout the years when research was conducted, confirms that in the present conditions, a Salmonella-free pig production chain is a difficult goal to achieve, and highlights the necessity of integrating a control plan at both the pre-harvest and slaughterhouse levels. The need for proper monitoring is also highlighted as CA sampling, provided by EU legislation only at the slaughterhouse level, could not be sufficient for rapid control intervention. Therefore, an integrated chain approach would be desirable to reduce the presence of these pathogens in pork and pork products.

Author Contributions: Conceptualization, S.P., D.R., and R.R.; methodology, A.Z.; validation, R.O. and A.V.; formal analysis, A.Z. and R.O.; investigation, S.P. and R.R.; resources, A.V.; data curation, S.P. and R.R., writing — original draft preparation, D.R., R.R., and S.P.; writing — review and editing: R.B. and T.S.K.; supervision, D.R. All authors have read and agreed to the published version of the manuscript. 
Funding: This research received no external funding.

Institutional Review Board Statement: Ethical review and approval were waived for this study due to the fact that the samples were obtained from regularly slaughtered animals during official control plans.

Informed Consent Statement: Not applicable.

Data Availability Statement: Data are available from the authors.

Conflicts of Interest: The authors declare no conflict of interest.

\section{References}

1. European Food Safety Authority \& European Centre for Disease Prevention and Control. The European Union One Health 2019 Zoonoses Report. EFSA J. 2021, 19, 6406.

2. ANVISA. Ministério da Saúde. Surtos de Doenças Transmitidas por Alimentos no Brasil. Available online: http://portalarquivos2 .saude.gov.br/images/pdf/2019/fevereiro/15/Apresenta----o-Surtos-DTA---Fevereiro-2019.pdf (accessed on 24 June 2021).

3. Centers for Disease Control and Prevention (CDC). Surveillance for Foodborne Disease Outbreaks, United States, 2017, Annual Report; Department of Health and Human Services: Atlanta, GA, USA, 2019.

4. Gurman, P.M.; Ross, T.; Kiermeier, A. Quantitative Microbial Risk Assessment of Salmonellosis from the Consumption of Australian Pork: Minced Meat from Retail to Burgers Prepared and Consumed at Home. Risk Anal. 2016, 38, $2625-2645$. [CrossRef]

5. Sodagari, H.R.; Wang, P.; Robertson, I.; Habib, I.; Sahibzada, S. Non-Typhoidal Salmonella at the Human-Food-of-Animal-Origin Interface in Australia. Animals 2020, 10, 1192. [CrossRef]

6. Wang, J.; Li, J.; Liu, F.; Cheng, Y.; Su, J. Characterization of Salmonella enterica Isolates from Diseased Poultry in Northern China between 2014 and 2018. Pathogens 2020, 9, 95. [CrossRef] [PubMed]

7. Graziani, C.; Mughini-Gras, L.; Owczarek, S.; Dionisi, A.M.; Luzzi, I.; Busani, L. Distribution of Salmonella Enterica Isolates from Human Cases in Italy, 1980 to 2011. Eurosurveillance 2013, 18, 20519. [CrossRef] [PubMed]

8. Piras, F.; Brown, D.; Meloni, D.; Mureddu, A.; Mazzette, R. Investigation of Salmonella Enterica in Sardinian Slaughter Pigs: Prevalence, Serotype and Genotype Characterization. Int. J. Food Microbiol. 2011, 151, 201-209. [CrossRef] [PubMed]

9. Andres, V.M.; Davies, R.H. Biosecurity Measures to Control Salmonella and Other Infectious Agents in Pig Farms: A Review. Compr. Rev. Food Sci. Food Saf. 2015, 14, 317-335. [CrossRef]

10. Campos, J.; Mourão, J.; Peixe, L.; Antunes, P. Non-Typhoidal Salmonella in the Pig Production Chain: A Comprehensive Analysis of Its Impact on Human Health. Pathogens 2019, 8, 19. [CrossRef]

11. Massacci, F.R.; Morelli, A.; Cucco, L.; Castinel, A.; Ortenzi, R.; Tofani, S.; Pezzotti, G.; Estellé, J.; Paniccià, M.; Magistrali, C.F. Transport to the Slaughterhouse Affects the Salmonella Shedding and Modifies the Fecal Microbiota of Finishing Pigs. Animals 2020, 10, 676. [CrossRef]

12. Bonardi, S.; Morganti, M.; Pupillo, G.; Brindani, F. Salmonella Brandenburg in the Pork Chain in Italy: Genetic Comparison with the Human Isolates. Ital. J. Food Saf. 2018, 7, 6938-6940. [CrossRef]

13. Hill, A.A.; Simons, R.; Swart, A.N.; Kelly, L.; Hald, T.; Snary, E.L. Assessing the Effectiveness of On-Farm and Abattoir Interventions in Reducing Pig Meat-Borne Salmonellosis within E.U. Member States. Risk Anal. 2016, 36, 546-560. [CrossRef]

14. Bonardi, S.; Alpigiani, I.; Bruini, I.; Barilli, E.; Brindani, F.; Morganti, M.; Cavallini, P.; Bolzoni, L.; Pongolini, S. Detection of Salmonella Enterica in Pigs at Slaughter and Comparison with Human Isolates in Italy. Int. J. Food Microbiol. 2016, 218, 44-50. [CrossRef]

15. Botteldoorn, N.; Heyndrickx, M.; Rijpens, N.; Grijspeerdt, K.; Herman, L. Salmonella on Pig Carcasses: Positive Pigs and Cross Contamination in the Slaughterhouse. J. Appl. Microbiol. 2003, 95, 891-903. [CrossRef]

16. Pesciaroli, M.; Cucco, L.; De Luca, S.; Massacci, F.; Maresca, C.; Medici, L.; Paniccià, M.; Scoccia, E.; Staffolani, M.; Pezzotti, G.; et al. Association between Pigs with High Caecal Salmonella Loads and Carcass Contamination. Int. J. Food Microbiol. 2017, 242, 82-86. [CrossRef] [PubMed]

17. Swanenburg, M.; Urlings, H.A.P.; Keuzenkamp, D.A.; Snijders, J.M.A. Salmonella in the Lairage of Pig Slaughterhouses. J. Food Prot. 2001, 64, 12-16. [CrossRef] [PubMed]

18. Marín, C.; Chinillac, M.C.; Cerdà-Cuéllar, M.; Dasí, L.M.; Navarro, S.S.; Ayats, T.; Marco-Jimenez, F.; Vega, S. Contamination of Pig Carcass with Salmonella Enterica Serovar Typhimurium Monophasic Variant 1,4[5],12:i:- originates mainly in live animals. Sci. Total. Environ. 2019, 703, 134609. [CrossRef] [PubMed]

19. Correia-Gomes, C.; Leonard, F.; Graham, D. Description of Control Programmes for Salmonella in Pigs in Europe. Progress to Date? J. Food Saf. 2021, e12916. [CrossRef]

20. Bersot, L.D.S.; Cavicchioli, V.Q.; Viana, C.; Burin, R.C.K.; Camargo, A.C.; de Almeida Nogueira Pinto, J.P.; Nero, L.A.; Destro, M.T. Prevalence, Antimicrobial Resistance, and Diversity of Salmonella along the Pig Production Chain in Southern Brazil. Pathogens 2019, 8, 204. [CrossRef]

21. EFSA Panel on Biological Hazards (BIOHAZ). Scientific Opinion on the Public Health Hazards to be Covered by Inspection of Meat (Swine). EFSA J. 2011, 9, 2351. [CrossRef] 
22. Sánchez-Rodríguez, J.; Navas, L.; Vinuesa, F.; Castells, C.; Martínez, M.; López, A.; Lindez, B.; Cabrera-Vique, C. New insights on the risk factors associated with the presence of Salmonella on pig carcasses. Lessons from small slaughterhouses. Food Control. 2018, 87, 46-52. [CrossRef]

23. Technical specifications on harmonised epidemiological indicators for public health hazards to be covered by meat inspection of swine. EFSA J. 2011, 9, 2371. [CrossRef]

24. European Commission. Commission Regulation (EC) No 2073/2005 of 15 November 2005 on microbiological criteria for foodstuffs. Off. J. Eur. Union 2005, 338, 1-26.

25. European Commission. Commission Regulation (EU) No 218/2014 of 7 March 2014 amending Annexes to Regulations (EC) No 853/2004 and (EC) No 854/2004 of the European Parliament and of the Council and Commission Regulation (EC) No $2074 / 2005$. Off. J. Eur. Union 2014, 69, 95-98.

26. AFNOR (AFNOR BIO 12/10-09/02). Available online: https://nf-validation.afnor.org/wp-content/uploads/2014/03/Synt-BIO12-10-09-02_en.pdf (accessed on 19 July 2021).

27. International Organization for Standardization. EN ISO 6579-1:2017. Microbiology of the Food Chain-Horizontal Method for the Detection, Enumeration and Serotyping of Salmonella-Part 1: Detection of Salmonella spp.; International Organization for Standardization: Geneve, Switzerland, 2017.

28. Grimont, P.A.D.; Weill, F.-X. Antigenic Formulae of the Salmonella Serovars. In WHO Collaborating Center for Ref-erence and Research on Salmonella, 9th ed.; Institut Pasteur: Paris, France, 2007; Available online: http:/ / www.scacm.org/free/Antigenic\%20 Formulae\%20of\%20the\%20Salmonella\%20Serovars\%202007\%209th\%20edition.pdf (accessed on 17 July 2021).

29. Epi Info 7.2, CDC Division of Health Informatics \& Surveillance (DHIS), Center for Surveillance, Epidemiology \& Laboratory Services (CSELS). Available online: https:/ / www.cdc.gov/epiinfo/index.html (accessed on 14 August 2021).

30. Ghafir, Y.; China, B.; Korsak, N.; Dierick, K.; Collard, J.-M.; Godard, C.; De Zutter, L.; Daube, G. Belgian Surveillance Plans To Assess Changes in Salmonella Prevalence in Meat at Different Production Stages. J. Food Prot. 2005, 68, 2269-2277. [CrossRef]

31. Cilia, G.; Turchi, B.; Fratini, F.; Bilei, S.; Bossù, T.; De Marchis, M.L.; Cerri, D.; Pacini, M.I.; Bertelloni, F. Prevalence, Virulence and Antimicrobial Susceptibility of Salmonella spp., Yersinia enterocolitica and Listeria monocytogenes in European Wild Boar (Sus scrofa) Hunted in Tuscany (Central Italy). Pathogens 2021, 10, 93. [CrossRef]

32. Zhou, Z.; Jin, X.; Zheng, H.; Li, J.; Meng, C.; Yin, K.; Xie, X.; Huang, C.; Lei, T.; Sun, X.; et al. The prevalence and load of Salmonella, and key risk points of Salmonella contamination in a swine slaughterhouse in Jiangsu province, China. Food Control. 2018, 87, 153-160. [CrossRef]

33. Powell, L.F.; Cheney, T.E.A.; Williamson, S.; Guy, E.; Smith, R.P.; Davies, R.H. A Prevalence Study of Salmonella spp., Yersinia spp., Toxoplasma gondii and Porcine Reproductive and Respiratory Syndrome Virus in UK Pigs at Slaughter. Epidemiol. Infect. 2015, 144, 1538-1549. [CrossRef]

34. Fois, F.; Piras, F.; Torpdahl, M.; Mazza, R.; Consolati, S.G.; Spanu, C.; Scarano, C.; De Santis, E.P.L. Occurrence, Characterization, and Antimicrobial Susceptibility of Salmonella Entericain Slaughtered Pigs in Sardinia. J. Food Sci. 2017, 82, 969-976. [CrossRef]

35. Di Ciccio, P.; Ossiprandi, M.C.; Zanardi, E.; Ghidini, S.; Belluzzi, G.; Vergara, A.; Ianieri, A. Microbiological Contamination in Three Large-Scale Pig Slaughterhouses in Northern Italy. Ital. J. Food Saf. 2016, 5, 6151. [CrossRef]

36. Arguello, H.; Carvajal, A.; Collazos, J.A.; García-Feliz, C.; Rubio, P. Prevalence and Serovars of Salmonella Enterica on Pig Carcasses, Slaughtered Pigs and the Environment of Four Spanish Slaughterhouses. Food Res. Int. 2012, 45, 905-912. [CrossRef]

37. Ghougal, K.; Dib, A.L.; Lakhdara, N.; Lamri, M.; Baghezza, S.; Azizi, A.; Merrad, R.; Zouikri, A.; Cheraitia, D.; Trouni, M.; et al. Risk factors related to bacterial contamination by Enterobacteriaceae and fecal coliforms and the prevalence of Salmonella spp. in Algerian farms, slaughterhouses and butcheries: A two-year follow-up study. Math. Biosci. Eng. 2021, 6, 768-785. [CrossRef]

38. Bonardi, S.; Bruini, I.; Magnani, R.; Cannistrà, N.; Brindani, F. Low Prevalence of Salmonella Enterica in Cull Dairy Cattle at Slaughter in Northern Italy. Ital. J. Food Saf. 2017, 6, 6172. [CrossRef]

39. Wheatley, P.; Giotis, E.S.; McKevitt, A.I. Effects of Slaughtering Operations on Carcass Contamination in an Irish Pork Production Plant. Ir. Vet. J. 2014, 67, 1. [CrossRef] [PubMed]

40. Baptista, F.; Dahl, J.; Nielsen, L. Factors influencing Salmonella carcass prevalence in Danish pig abattoirs. Prev. Veter. Med. 2010, 95, 231-238. [CrossRef]

41. Magossi, G.; Bai, J.; Cernicchiaro, N.; Jones, C.; Porter, E.; Trinetta, V. Seasonal Presence of Salmonella spp., Salmonella Typhimurium and Its Monophasic Variant Serotype I 4,[5],12:i:-, in Selected United States Swine Feed Mills. Foodborne Pathog. Dis. 2019, 16, 276-281. [CrossRef] [PubMed]

42. Arguello, H.; Alvarez-Ordóñez, A.; Carvajal, A.; Rubio, P.; Prieto, M. Role of Slaughtering in Salmonella Spreading and Control in Pork Production. J. Food Prot. 2013, 76, 899-911. [CrossRef] [PubMed]

43. European Commission. Commission Regulation (EC) No 2160/2003 of the European Parliament and of the Council of 17 November 2003 on the Control of Salmonella and Other Specified Food-Borne Zoonotic Agents. Off. J. Eur. Union 2003, $325,1-15$.

44. Martínez-Avilés, M.; Garrido-Estepa, M.; Álvarez, J.; De La Torre, A. Salmonella Surveillance Systems in Swine and Humans in Spain: A Review. Veter. Sci. 2019, 6, 20. [CrossRef]

45. European Commission. Commission Regulation (EC) No. 852/2004 of the European Parliament and of the Council of 29 April 2004 on the Hygiene of Foodstuffs. Off. J. Eur. Union 2004, 139, 1-23.

46. European Commission. Regulation (EU) of the Commission No 217/2014 of 7 March 2014 amending Regulation (EC) No 2073/2005 as Regards Salmonella in Pig Carcases. Off. J. Eur. Union 2014, 69, 93-94. 
47. Møgelmose, V.; Lindegaard, L.L.; Dahl, J. A Sudden Increase in Salmonella-How the Surveillance System Reacted: A Danish Experience. In Proceedings of the 12th International Symposium on the Epidemiology and Control of Biological, Chemical and Physical Hazards in Pigs and Pork, Foz doIguaçu, Brazil, 21-24 August 2017; pp. 116-120. [CrossRef]

48. SANCO/2008/E2/036. Analysis of the Costs and Benefits of Setting a Target for the Reduction of Salmonella in Slaughter Pigs", Report for EUROPEAN COMMISSION Health and Consumers Directorate-General, June 2010. Available online: https:/ / ec.europa.eu/food/system/files/2016-10/biosafety_food-borne-disease_salmonella_fattening-pigs_slaughthouseanalysis-costs.pdf (accessed on 20 July 2021). 